\title{
$\begin{array}{ll}\text { Research Square } & \begin{array}{l}\text { Preprints are preliminary reports that have not undergone peer review. } \\ \text { They should not be considered conclusive, used to inform clinical practice, } \\ \text { or referenced by the media as validated information. }\end{array}\end{array}$
}

\section{Transbronchial Lung Cryobiopsy May be of Value for Nonresolving Acute Respiratory Distress Syndrome: Case series and Systematic literature Review}

Guowu Zhou

China-Japan Friendship Hospital

Yingying Feng

China-Japan Friendship Hospital

Shiyao Wang

China-Japan Friendship Hospital

Yi Zhang

China-Japan Friendship Hospital

Ye Tian

China-Japan Friendship Hospital

\section{Xiaojing Wu}

China-Japan Friendship Hospital

Ling Zhao

China-Japan Friendship Hospital

Dan Wang

China-Japan Friendship Hospital

Yi Li

China-Japan Friendship Hospital

Zheng Tian

China-Japan Friendship Hospital

Qingyuan Zhan ( $\nabla$ drzhanqy@163.com )

China-Japan Friendship Hospital https://orcid.org/0000-0003-0021-0270

Research article

Keywords: TBLC, ARDS, biopsy, safety, diagnostic yield

Posted Date: March 3rd, 2020

DOI: https://doi.org/10.21203/rs.3.rs-15884/v1

License: (c) (1) This work is licensed under a Creative Commons Attribution 4.0 International License. Read Full License

Version of Record: A version of this preprint was published on June 29th, 2020. See the published version at https://doi.org/10.1186/s12890-020-01203-w. 


\section{Abstract}

Background: Identifying pathologic features is helpful for management of nonresolving acute respiratory distress syndrome (ARDS). Transbronchial lung cryobiopsy (TBLC) is a novel biopsy technique which may be comparable to surgical biopsy. The aim of this study was to assess the value of TBLC in patients with nonresolving ARDS.

Methods: All patients with nonresolving ARDS who underwent TBLC from January 2019 to August 2019 in a tertiary medical ICU were included. In addition, a literature search of TBLC for ARDS was performed by searching PubMed, EMBASE, ATS/ERS/APSR meeting abstracts, clinicaltrial.gov, and Google Scholar. Data on complications, histologic diagnosis, management changes, and outcomes were analyzed.

Results: Five patients (three women and two men) underwent TBLC. None of the patients developed pneumothorax although in two patients massive bleeding occurred, which was stopped by continuous occlusion using bronchial blockers. There were no procedure-related deaths. Diffuse alveolar damage (DAD) and alternative histologic patterns were found in two and three patients, respectively, resulting in management changes in all cases. The literature search yielded four studies, which together with the present study resulted in data from 25 cases in which TBLC was used in nonresolving ARDS. The summary diagnostic yield was $92 \%(23 / 25)$. Only $44 \%(11 / 25)$ of the cases were proven to be DAD. TBLC contributed to management changes in $80 \%$ of the patients (20/25). Procedure-related complications consisted of pneumothorax $(16 \%, 4 / 25)$, significant bleeding $(12 \%, 3 / 25)$, and persistent air leak $(8 \%, 2 / 25)$. There were no procedure-related deaths. The follow-up survival rate was $61.9 \%(13 / 21)$

Conclusions: Given its acceptable safety profile and high diagnostic yield, TBLC may be of potential value in patients with nonresolving ARDS.

\section{Background}

Acute respiratory distress syndrome (ARDS) is common in critically ill patients. The majority of studies report a high rate of morbidity and a mortality rate in the range of $35-60 \%(1,2)$. The Berlin definition of ARDS takes into account clinical and radiological criteria in the diagnosis and classification without consideration of pathologic findings (3). Diffuse alveolar damage (DAD) is a typical pathological finding in ARDS (4) but it is not seen in all ARDS patients nor is it specific to the disease. Studies revealed only $43-45 \%$ of ARDS had DAD (5-8). Identifying the pathologic pattern in nonresolving ARDS can facilitate treatment decision-making and improve outcomes $(6,8)$.

When the inciting event that results in ARDS is unclear or when an alternative diagnosis is under consideration, OLB is one of the most common procedures to obtain a histologic diagnosis. Several studies have shown a positive impact of the histologic results of OLB in patients with nonresolving ARDS (6,8). However, OLB is performed in only $4-7 \%$ of patients with ARDS $(6,9)$, due to the high surgery risk and poor condition of most patients who are candidates for the procedure. Moreover, the complication rate of OLB is about $30 \%$, with complications including persistent air leak and bleeding (9). The use of less invasive procedure, such as transbronchial lung biopsy (TBLB), in clinical practice has been limited due to difficulties in obtaining adequate tissue to provide confident pathologic results (the diagnostic yield is $<35 \%)(9,10)$. Transbronchial lung cryobiopsy (TBLC) is an alternative technique that has been widely used in the diagnosis of diffuse parenchymal lung disease (DPLD) (11). The sample sizes are significantly larger than those obtained with TBLB, and the diagnostic yield approaches that of surgical lung biopsy and complications were less $(12,13)$. These observations suggest TBLC as an alternative procedure to OLB in patients with nonresolving ARDS, with the potential benefits including adequate tissue to identify pathologies and less invasiveness. However, to the best of our knowledge, the use of TBLC in nonresolving ARDS has been examined in only a few case reports. Thus, in this study, we assessed the use of TBLC in nonresolving ARDS based on 25 cases from our institute and searched from literature.

\section{Methods}

Patients

TBLC was conducted in the event of persistent respiratory failure after ongoing lung infection was ruled out or when an alternative diagnosis was suspected based on the patient's history, clinical and radiologic presentation. The hospital records of all ARDS patients who underwent TBLC from January 2019 to August 2019 in our 26-bed tertiary medical ICU were reviewed. The inclusion criteria were as follows: age $\geq 18$ years at the time of TBLC, findings consistent with the Berlin ARDS definition, and ARDS characterized as mild, moderate or severe, as described in the Berlin definition, at the time of diagnosis and biopsy.

\section{TBLC procedure}

Five patients with ARDS underwent TBLC (Fig. 1). In four, the procedure was performed at the ICU bedside through an endotracheal tube, with the patient under deep sedation and supported by pressure control ventilation $\left(\mathrm{F}_{\mathrm{i}} \mathrm{O}_{2} 100 \%\right.$, PEEP $\left.0 \mathrm{cmH}_{2} \mathrm{O}\right)$ or combined with extracorporeal membrane oxygenation (ECMO). The fifth patient received TBLC in a hybrid cone beam computed tomography (CBCT) OR. The procedure was conducted by rigid bronchoscopy with the patient under general anesthesia and ventilated by high-frequency jet respirator ( $\mathrm{F}_{\mathrm{i}} \mathrm{O}_{2} 100 \%$, respiratory rate $60 \mathrm{bpm}$, tidal volume $\left.500 \mathrm{~mL}\right)$. In the four bedside procedures, flexible bronchoscopes were introduced into the target lobe bronchus through an endotracheal tube, and bronchial blockers were placed at the origin of the target lobe via the nasal tract. Radial probe endobronchial ultrasound (RP-EBUS) (EU-ME1, Olympus, Tokyo, Japan) was used to identify the proper biopsy site (Fig. 1A). Under the guidance of pre-procedure CT images, the bronchoscope was advanced into the potential target bronchi as far as possible and then retracted $1-2 \mathrm{~cm}$. When the surrounding of RP-EBUS showed heterogeneous echo without vascular presentation, the depth of the probe was marked. A $2.4 \mathrm{~mm}$ cryoprobe (ERBE, Solingen, Germany) was inserted to the same position (Fig. 1B). Cryobiopsy was performed (freeze time: 4 s) following probe positioning, using carbon dioxide as the cryogen (Fig. 1D). After each biopsy, the bronchial balloon blocker (CRE balloon, Boston Scientific Microvasive, Natick, MA, USA) was immediately filled (0.5-1 atm) to stop bleeding (Fig. 1E). Two to five biopsies were performed in each patient and the sizes of the obtained samples were measured. In the patient who underwent TBLC in the hybrid OR, flexible bronchoscopy and bronchial blocker were inserted through a

Page 2/9 
rigid bronchoscope. Prior to TBLC, CBCT images (Artis Zee III ceiling, Siemens AG, Munich, Germany) were acquired to determine the exact position of the cryoprobe (Fig. 1C2), which was placed under RP-EBUS guidance.

In patients with ECMO, the plan was to stop treatment with unfractionated heparin (UFH) $4 \mathrm{~h}$ before TBLC and then monitor the activated clotting time of whole blood (ACT). TBLC was performed when the ACT had decreased to within an acceptable range. After the procedure, the bronchial blocker was not removed until UFH had been reinitiated (Fig. 1F) and the ACT had recovered to the level previously achieved during ECMO and no active bleeding occurred.

\section{Outcomes}

Patients routinely underwent a post-procedure chest X-ray to screen for pneumothorax. Bleeding severity was graded on a scale of 4: no bleeding, mild bleeding (requiring suction to clear but no other endoscopic procedures), moderate bleeding (requiring endoscopic procedures such as bronchial occlusioncollapse and/or instillation of ice-cold saline) and severe bleeding (causing hemodynamic or respiratory instability, requiring tamponade or other surgical interventions, transfusions) (14). Other complications, if any, were recorded.

Data on pathological diagnosis, treatment changes after TBLC and survival outcomes were obtained from the patient's medical records.

Literature search strategy

A literature search of PubMed, EMBASE, ATS meeting abstracts, ERS meeting abstracts, APSR meeting abstract, clinicaltrial.gov, and Google Scholar ending on November 25, 2019 was conducted using the following terms: "acute respiratory distress syndrome" or "ARDS," and "cryobiopsy" or "cryoprobe," without restrictions on language or publication year. Then the retrieved papers were read in their entirety to assess their appropriateness for this study of the value of TBLC in ARDS. Data on the characteristics of the TBLC procedure, related complications, pathological diagnosis, treatment changes and patient survival outcomes were extracted and summary proportions were calculated based on individual cases.

\section{Results}

Patient characteristics

Five patients (three women and two men) with nonresolving ARDS underwent TBLC at our hospital. Their average age was 53 years (range: $31-68$ years). The characteristics of these patients are summarized in Table 1. Four of them had underlying disease, including multiple sclerosis, nephrotic syndrome, impaired glucose tolerance and advanced lung adenocarcinoma. Four of the patients were diagnosed with severe ARDS and one with moderate ARDS according to the Berlin definition. All four patients with severe ARDS received mechanical ventilation (MV) support, including two in combination with veno-venous ECMO. UFH was used in patients with ECMO but was stopped $4 \mathrm{~h}$ before TBLC in one patient. In the other (patient 1), because flow-through ECMO decreased significantly after UFH was stopped, heparin use was continued until $30 \mathrm{~min}$ before the biopsy procedure. Respiratory support in patients with moderate ARDS consisted of high-flow nasal cannula oxygen therapy (HFNC). 
Table 1

Clinical characteristics in nonresolving acute respiratory distress syndrome (ARDS) patients undergoing transbronchial lung cryobiopsy (TBLC).

\begin{tabular}{|c|c|c|c|c|c|c|c|c|c|c|c|}
\hline Case & $\begin{array}{l}\text { Age } \\
\text { (years), } \\
\text { gender }\end{array}$ & $\begin{array}{l}\text { Underly } \\
\text { diseases }\end{array}$ & $\begin{array}{l}\text { ARDS } \\
\text { severity }\end{array}$ & $\begin{array}{l}\text { Ventilation } \\
\text { settings }\end{array}$ & Guidance & $\begin{array}{l}\text { Freezing } \\
\text { time }\end{array}$ & $\begin{array}{l}\text { Sample } \\
\text { number } \\
\text { and } \\
\text { size }\end{array}$ & Complication & $\begin{array}{l}\text { Finial } \\
\text { pathology }\end{array}$ & $\begin{array}{l}\text { Management } \\
\text { changes }\end{array}$ & Outcon \\
\hline 1 & $39 / F$ & MS & Severe & $\begin{array}{l}\mathrm{PCV}(\mathrm{PC} \\
14 \mathrm{cmH}_{2} \mathrm{O}, \\
\mathrm{F}_{\mathrm{i}} \mathrm{O}_{2} 90 \% \text {, } \\
\mathrm{PEEP} 11 \\
\left.\mathrm{cmH}_{2} \mathrm{O}\right) \\
\text { and } \mathrm{ECMO} \\
(4500 \mathrm{rpm} \text {, } \\
\text { blood flow } \\
6.3 \mathrm{~L} / \mathrm{min} \text {, } \\
\text { gas flow } \\
4 \mathrm{~L} / \mathrm{min}, \\
\mathrm{F}_{\mathrm{i}} \mathrm{O}_{2} \\
100 \%)\end{array}$ & RP-EBUS & $2.4 \mathrm{~mm} / 4 \mathrm{~s}$ & $\begin{array}{l}2 / 20 \\
30 \\
\mathrm{~mm}^{2}\end{array}$ & $\begin{array}{l}\text { Severe } \\
\text { bleeding }\end{array}$ & $\begin{array}{l}\text { Fibrotic } \\
\text { phase of } \\
\text { DAD with } \\
\text { underly } \\
\text { infection }\end{array}$ & $\begin{array}{l}\text { changes in } \\
\text { antibiotic drugs } \\
\text { and steroid } \\
\text { discontinuation }\end{array}$ & Died \\
\hline 2 & $68 / \mathrm{M}$ & NS & Severe & $\begin{array}{l}\mathrm{PCV}(\mathrm{PC} \\
16 \mathrm{cmH}_{2} \mathrm{O} \text {, } \\
\mathrm{F}_{\mathrm{i}} \mathrm{O}_{2} 40 \% \text {, } \\
\mathrm{PEEP} 6 \\
\left.\mathrm{cmH}_{2} \mathrm{O}\right) \\
\text { and } \mathrm{ECMO} \\
(3120 \mathrm{rpm} \text {, } \\
\text { blood flow } \\
3.86 \mathrm{~L} / \mathrm{min} \text {, } \\
\text { gas flow } \\
3.5 \mathrm{~L} / \mathrm{min} \text {, } \\
\mathrm{F}_{\mathrm{i}} \mathrm{O}_{2} \\
100 \%)\end{array}$ & RP-EBUS & $2.4 \mathrm{~mm} / 4 \mathrm{~s}$ & $\begin{array}{l}3 / 12 \\
20,35 \\
\mathrm{~mm}^{2}\end{array}$ & $\begin{array}{l}\text { Mild } \\
\text { bleeding }\end{array}$ & $\begin{array}{l}\text { Proliferative } \\
\text { phase of } \\
\text { DAD with } \\
\text { CMV } \\
\text { inclusion }\end{array}$ & $\begin{array}{l}\text { initiation of } \\
\text { high-dose } \\
\text { steroid and } \\
\text { antivirus } \\
\text { treatment }\end{array}$ & Rehab \\
\hline 3 & $62 / F$ & IGT & Severe & $\begin{array}{l}\mathrm{PCV}(\mathrm{PC} \\
24 \mathrm{cmH}_{2} \mathrm{O}, \\
\mathrm{F}_{\mathrm{i}} \mathrm{O}_{2} 70 \% \\
\mathrm{PEEP} 10 \\
\left.\mathrm{cmH}_{2} \mathrm{O}\right)\end{array}$ & RP-EBUS & $2.4 \mathrm{~mm} / 4 \mathrm{~s}$ & $\begin{array}{l}4 / 9,12, \\
16,25 \\
\mathrm{~mm}^{2}\end{array}$ & $\begin{array}{l}\text { Mild } \\
\text { bleeding }\end{array}$ & $\begin{array}{l}\text { Foreign } \\
\text { body } \\
\text { granulomas }\end{array}$ & $\begin{array}{l}\text { initiation of } \\
\text { high-dose } \\
\text { steroid and a } \\
\text { determination } \\
\text { of the } \\
\text { aspiration } \\
\text { etiology }\end{array}$ & Rehab \\
\hline 4 & $65 / F$ & $\mathrm{CA}$ & Severe & $\begin{array}{l}\mathrm{PCV}(\mathrm{PC} \\
20 \mathrm{cmH}_{2} \mathrm{O}, \\
\mathrm{F}_{\mathrm{i}} \mathrm{O}_{2} 100 \% \text {, } \\
\mathrm{PEEP} 8 \\
\left.\mathrm{CmH}_{2} \mathrm{O}\right)\end{array}$ & RP-EBUS & $2.4 \mathrm{~mm} / 4 \mathrm{~s}$ & $\begin{array}{l}4 / 9,12, \\
16,25 \\
\mathrm{~mm}^{2}\end{array}$ & $\begin{array}{l}\text { Severe } \\
\text { bleeding }\end{array}$ & $\begin{array}{l}\text { Fibrotic } \\
\text { NSIP }\end{array}$ & $\begin{array}{l}\text { steroid } \\
\text { discontinuation } \\
\text { and } \\
\text { transitioned to } \\
\text { palliative } \\
\text { measures }\end{array}$ & Died \\
\hline 5 & $31 / \mathrm{M}$ & & moderate & $\begin{array}{l}\mathrm{HFNC} \\
\left(\mathrm{F}_{\mathrm{i}} \mathrm{O}_{2} 40 \% \text {, }\right. \\
\text { gas flow } \\
\text { rate } \\
60 \mathrm{~L} / \mathrm{min})\end{array}$ & $\begin{array}{l}\text { RP-EBUS } \\
\text { and } \\
\text { CBCT }\end{array}$ & $2.4 \mathrm{~mm} / 4 \mathrm{~s}$ & $\begin{array}{l}4 / 9,15 \\
24,42 \\
\mathrm{~mm}^{2}\end{array}$ & $\begin{array}{l}\text { Mild } \\
\text { bleeding }\end{array}$ & OP & $\begin{array}{l}\text { initiation of } \\
\text { high-dose } \\
\text { steroid }\end{array}$ & Rehab \\
\hline
\end{tabular}

M, man; F, woman; MS, multiple sclerosis; NS, nephrotic syndrome; IGT, impaired glucose tolerance; CA, lung adenocarcinoma; PCV, pressure control ventilation; PEEP, positive end expiratory pressure; PC, pressure control above PEEP; ECMO, extracorporeal membrane oxygenation; RP-EBUS, radial probe endobronchial ultrasound; CBCT, cone beam computed tomography; DAD, diffuse alveolar damage; HFNC, high-flow nasal cannula oxygen therapy; CMV, cytomegalovirus; NSIP, non-specific interstitial pneumonia; OP, organized pneumonia; Rehab, rehabilitation.

TBLC procedure

All TBLC procedures were successfully performed using a $2.4 \mathrm{~mm}$ cryoprobe (freeze time: $4 \mathrm{~s}$ ). A mean of 3.2 samples (range: $2-4$ samples) were obtained from one (1 patient) or two (4 patients) lung segments. The samples had a mean size of $27.1 \mathrm{~mm}^{2}$ (surface area) and were deemed satisfactory for use in histopathology and tissue culture (Fig. 2). The patient with moderate ARDS successfully recovered from general anesthesia and was placed on HFNC after TBLC. None of the patients experienced significant oxygenation state changes before or after the procedure. No patient developed pneumothorax but two patients suffered massive bleeding, which ceased after 2 and $3 \mathrm{~h}$, respectively, in response to tamponades using bronchial blockers. There was no incident of hemodynamic instability. Three other patients had mild bleeding. There were no procedure-related deaths. The bronchial balloon blockers in patients with ECMO were removed after the confirmation of no active bleeding following the reinitiation of UFH.

Outcomes

The histopathological diagnosis in the five patients included a fibrotic phase of DAD with underlying infection $(n=1)$, proliferative phase of DAD with cytomegalovirus inclusions $(n=1)$, foreign body granulomas $(n=1)$, fibrotic non-specific interstitial pneumonia $(n=1)$ and OP $(n=1)$. One patient had an Acinetobacter baumanii infection, confirmed by tissue culture. Management changes were made in all patients according to the TBLC results, including 
changes in antibiotic drugs and steroid usage (Table 1). Three patients improved and subsequently underwent rehabilitation treatments. Two patients died, one due to pulmonary embolism and the other to septic shock.

Systematic review

Four studies (2 meeting abstracts, 1 published letter and 1 published paper) met the inclusion criteria (15-18) (Fig. 3). The patients in two studies (15,18) overlapped such that finally three previous investigations of 20 patients with nonresolving ARDS who underwent TBLC were included (15-17). Thus, together with our five patients, a total of 25 patients who met the criteria of the Berlin definition of ARDS were included in our larger study. The characteristics of these four studies are summarized in Table 2. All of the studies were retrospective case series. In the study of Dincer et al. (15), the five patients with ARDS were on $\mathrm{MV}$ and a mean of five specimens was obtained from each patient. A specific histopathological diagnosis was made and contributed to management changes in all patients. The pathological pattern included 2 DAD and 3 alternative diagnosis. There were no procedure-related complications. Four of the five patients survived. Cooley et al. (16) reviewed 11 cases of ARDS in patients under MV support. The diagnostic yield of TBLC was $82 \%$ (9/11), including four DAD. TBLC resulted in management changes in eight patients. Complications included pneumothorax $(n=4)$, persistent air leak $(n=2)$, and significant bleeding $(n=1)$. Six patients survived. Las Heras et al. (17) reported on four ARDS patients, and a specific histopathological diagnosis was made in each case, including DAD $(n=3)$ and another pattern $(n=1)$. TBLC contributed to management changes in two patients. There were no incidents of pneumothorax, significant bleeding or procedure-related death. The survival outcome was not available.

Table 2

Characteristics of the included studies with nonresolving acute respiratory distress syndrome (ARDS) patients undergoing transbronchial lung cryobiopsy (TBLC).

\begin{tabular}{|c|c|c|c|c|c|c|}
\hline Study / year & $\begin{array}{l}\text { Number of } \\
\text { patients }\end{array}$ & $\begin{array}{l}\text { Ventilation } \\
\text { support }\end{array}$ & $\begin{array}{l}\text { Final pathology } \\
\text { diagnosis }\end{array}$ & $\begin{array}{l}\text { Management } \\
\text { changes }\end{array}$ & Complications & Survivals \\
\hline $\begin{array}{l}\text { Dincer et } \\
\text { al./2018 }\end{array}$ & 5 & MV & $\begin{array}{l}5 / 5(2 \mathrm{DAD}, 2 \mathrm{OP} \text { and } \\
1 \text { IPS) }\end{array}$ & $5 / 5$ & None & $4 / 5$ \\
\hline $\begin{array}{l}\text { Cooley et } \\
\text { al./2019 }\end{array}$ & 11 & MV & $\begin{array}{l}9 / 11 \text { (4DAD, } 2 \mathrm{COP} \\
\text { and } 3 \text { others) }\end{array}$ & $8 / 11$ & $\begin{array}{l}4 \text { pneumothorax, } 2 \text { persistent air leak, } 1 \\
\text { significant bleeding }\end{array}$ & $6 / 11$ \\
\hline $\begin{array}{l}\text { Las Heras et } \\
\text { al./2019 }\end{array}$ & 4 & MV & $\begin{array}{l}\text { 4/4 (3 DAD and } 1 \\
\text { other) }\end{array}$ & $2 / 4$ & None & NA \\
\hline Current study & 5 & $\begin{array}{l}\text { MV and } \\
\text { ECMO }\end{array}$ & $\begin{array}{l}5 / 5(2 \mathrm{DAD} \text { and } 3 \\
\text { others) }\end{array}$ & $5 / 5$ & 2 significant bleeding & $3 / 5$ \\
\hline Summary & 25 & - & $23 / 25(11 / 25 \mathrm{DAD})$ & $20 / 25$ & $\begin{array}{l}4 / 25 \text { pneumothorax, } 3 / 25 \text { significant bleeding, } \\
2 / 25 \text { persistent air leak }\end{array}$ & $13 / 21$ \\
\hline
\end{tabular}

According to the summary proportions from these four studies, the diagnostic yield of TBLC for nonresolving ARDS was $92 \%$ (23/25). DAD was diagnosed in $44 \%(11 / 25)$ of the patients; the remainder had other diagnoses. TBLC contributed to management changes in $80 \%(20 / 25)$ of the patients. Procedure-related complications included pneumothorax $(16 \%, 4 / 25)$, significant bleeding $(12 \%, 3 / 25)$ and persistent air leak $(8 \%, 2 / 25)$. There were no procedure-related deaths. The follow-up survival rate was $61.9 \%(13 / 21)$.

\section{Discussion}

We assessed the safety and value of TBLC for ARDS in five patients with nonresolving ARDS at our hospital and then in a larger study that also included all patients from previous studies.

TBLC was most often used in patients with DPLD. The most recent study (13) indicated that the diagnostic yield of TBLC was comparable to that of OLB, with a high level of diagnostic agreement between the two procedures. However, The safety and potential value of TBLC in ARDS has not been established. Our literature search of this topic was conducted and resulted in the identification of only three independent studies with a total of 20 patients (15-17). Our combined analyses suggested that the complications of TBLC in ARDS are acceptable and similar to those reported for TBLC used in DPLD at stable stage. In a recent meta-analysis of DPLD patients who underwent TBLC (12), the incidence of significant bleeding was $14.2 \%(0-42 \%)$ and that of pneumothorax $9.4 \%$ $(0-30 \%)$. Compared to OLB, TBLC has a better safety profile and is more likely to harvest sufficient tissue to allow a confident diagnosis, possibly resulting in patient management changes. Wong et al. also conducted a meta-analysis and showed that OLB could lead to therapeutic changes in 78\% of ARDS patients while procedure-related complications occurred in $29 \%$, most commonly persistent air leak ( $71 \%$ of complications) (19). In our study based on the combined data of reported cases, the summary diagnostic yield of TBLC was $92 \%$, and $56 \%$ of the patients had a diagnosis other than DAD, which led to management changes in $80 \%$. Only $8 \%$ of patients had persistent air leak. These results indicate that TBLC offers an alternative biopsy method to OLB for patients with nonresolving ARDS.

Patients with ARDS usually have complex underlying conditions that increase the difficulty and risk of TBLC. ECMO is an important life support method for patients with severe ARDS. Most of these patients receive UFH to prevent thrombus formation and maintain normal ECMO operation, although the risk for procedure-related bleeding is then higher. The use of TBLC in ARDS patients on ECMO was not previously described. However, our study included two patients with severe ARDS who were on ECMO support in whom TBLC was successfully performed. One of them suffered from procedure-related massive bleeding, 
which was successfully stopped by $3 \mathrm{~h}$ of continuous occlusion using bronchial blockers. Thus, in patients with ECMO TBLC should be performed after controlling for the bleeding risk and thrombogenesis, and bronchial blockers should be placed prophylactically.

The safety of TBLC depends to a large extent on the location of the cryoprobe (20). A distance of $<1 \mathrm{~cm}$ to the pleura is associated with a significantly higher risk for pneumothorax, and a biopsy obtained too proximal to the middle third of the lung increases the risk for severe bleeding. RP-EBUS can identify diffuse lung lesions and their surrounding vessels and very encouraging results have been obtained using RP-EBUS-guided TBLC in patients with ILD (21,22). Our study is the first to describe the use of RP-EBUS-guided TBLC in ARDS. Four patients with severe ARDS underwent ICU bedside TBLC guided only by RP-EBUS. The patient with moderate ARDS underwent TBLC in a hybrid OR with the combined guidance of CBCT and RP-EBUS. None of the patients developed pneumothorax but two had massive bleeding. Thus, the value of RP-EBUS guidance requires further investigations in larger populations.

By including all patients from current and previous studies, our study was the largest case series to preliminarily assess the safety and value of TBLC in ARDS. However, it had several limitations. First, it was a retrospective study, although the results point out the need for a prospective controlled study with larger population. Second, the procedure protocols were not absolutely the same between studies. Further investigations should be conducted on the basis of a standard TBLC protocol for patients with ARDS.

\section{Conclusion}

The complications of TBLC in patients with ARDS were acceptable. The procedure had a high diagnostic yield and led to a re-evaluation of the diagnosis as well as changes in patient management. TBLC might therefore be of value in patients with nonresolving ARDS. Further investigations with a prospective design and a larger number of patients are warranted.

\section{Abbreviations}

ARDS, acute respiratory distress syndrome; ILD, interstitial lung disease; OLB, open lung biopsy; OR, operating room; TBLB, transbronchial lung biopsy; TBLC, Transbronchial lung cryobiopsy; RP-EBUS, radial probe endobronchial ultrasound; ACT, activated clotting time of whole blood; UFH, unfractionated heparin; PCV, pressure control ventilation; PEEP, positive end expiratory pressure; PC, pressure control above PEEP; ECMO, extracorporeal membrane oxygenation; RPEBUS, radial probe endobronchial ultrasound; $C B C T$, cone beam computed tomography; DAD, diffuse alveolar damage; HFNC, high-flow nasal cannula oxygen therapy; CMV, cytomegalovirus; NSIP, non-specific interstitial pneumonia; OP, organized pneumonia; COP, cryptogenic organizing pneumonia.

\section{Declarations}

Ethics approval and consent to participate:

The Institutional Ethics Committee (China-Japan Friendship Hospital) approved this study. The written informed consent from the patients or their next of kin was obtained.

Consent for publication:

The consent for publication from the patients or their next of kin was obtained.

Availability of data and materials:

The datasets used and analysed during the current study are available from the corresponding author on reasonable request.

Competing interests:

All authors declared no competing interest existed in this study.

Funding:

This study was supported by the Fund of The National Key Research and Development Program of China (No. 2016YFC1304300), National Natural Science Foundation of China (No 81870072), CAMS Innovation Fund for Medical Sciences (No.2018-I2M-1-003) and Non-profit Central Research Institute Fund of CAMS (2019TX320006). We used the funds to access to publications which are not open access. The funding sponsors had no role in design of the study, or in the collection, analyses, interpretation of data, or in the writing of the manuscript, or the decision to publish.

Author contributions: 
GZ analyzed and interpreted the patient data and was a major contributor in writing the manuscript. YF and SW contributed to the acquisition and analysis.

YZ, YT and XW contributed to substantively revised the manuscript. LZ performed the histological examination of the specimens. DW, YL and ZT contributed to the literature search and analysis. QZ contributed to the conception and design of the work. All authors read and approved the final manuscript.

Acknowledgements:

Not applicable.

\section{References}

1. Bellani G, Laffey JG, Pham T, Fan E, Brochard L, Esteban A, et al. Epidemiology, Patterns of Care, and Mortality for Patients With Acute Respiratory Distress Syndrome in Intensive Care Units in 50 Countries. JAMA. 2016;315:788-800.

2. Vincent JL, Sakr Y, Ranieri VM: Epidemiology and outcome of acute respiratory failure in intensive care unit patients. Crit Care Med. 2003;31:S296-9.

3. ARDS Definition Task Force, Ranieri VM, Rubenfeld GD, Thompson BT, Ferguson ND, Caldwell E, et al. Acute respiratory distress syndrome: the Berlin Definition. JAMA. 2012;307:2526-33.

4. Tomashefski JF Jr. Pulmonary pathology of acute respiratory distress syndrome. Clin Chest Med. 2000;21:435-66.

5. Thille AW, Esteban A, Fernández-Segoviano P, Rodriguez JM, Aramburu JA, Peñuelas O, et al. Comparison of the Berlin definition for acute respiratory distress syndrome with autopsy. Am J Respir Crit Care Med. 2013;187:761-7.

6. Gerard L, Bidoul T, Castanares-Zapatero D, Wittebole X, Lacroix V, Froidure A, et al. Open Lung Biopsy in Nonresolving Acute Respiratory Distress Syndrome Commonly Identifies Corticosteroid-Sensitive Pathologies, Associated With Better Outcome. Crit Care Med. 2018;46:907-14.

7. Guerin C, Bayle F, Leray V, Debord S, Stoian A, Yonis H, et al. Open lung biopsy in nonresolving ARDS frequently identifies diffuse alveolar damage regardless of the severity stage and may have implications for patient management. Intensive Care Med. 2015;41:222-30.

8. Papazian L, Doddoli C, Chetaille B, Gernez Y, Thirion X, Roch A, et al. A contributive result of open-lung biopsy improves survival in acute respiratory distress syndrome patients. Crit Care Med. 2007;35:755-62.

9. Palakshappa JA, Meyer NJ. Which patients with ARDS benefit from lung biopsy? Chest. 2015;148:1073-82.

10. O'Brien JD, Ettinger NA, Shevlin D, Kollef MH. Safety and yield of transbronchial biopsy in mechanically ventilated patients. Crit Care Med. 1997;25:440-6.

11. Babiak A, Hetzel J, Krishna G, Fritz P, Moeller P, Balli T, et al. Transbronchial cryobiopsy: a new tool for lung biopsies. Respiration. 2009;78:203-8.

12. Sethi J, Ali MS, Mohananey D, Nanchal R, Maldonado F, Musani A. Are Transbronchial Cryobiopsies Ready for Prime Time?: A Systematic Review and Meta-Analysis. J Bronchology Interv Pulmonol. 2019;26:22-32.

13. Troy LK, Grainge C, Corte TJ, Williamson JP, Vallely MP, Cooper WA, et al. Cryobiopsy versus Open Lung biopsy in the Diagnosis of Interstitial lung disease alliance (COLDICE) Investigators. Diagnostic accuracy of transbronchial lung cryobiopsy for interstitial lung disease diagnosis (COLDICE): a prospective, comparative study. Lancet Respir Med. 2019 pii: S2213-2600(19)30342-X.

14. Ravaglia C, Bonifazi M, Wells AU, Tomassetti S, Gurioli C, Piciucchi S, et al. Safety and diagnostic yield of transbronchial lung cryobiopsy in diffuse parenchymal lung diseases: a comparative study versus video-assisted thoracoscopic lung biopsy and a systematic review of the literature. Respiration. 2016;91:215-27.

15. Dincer HE, Zamora F, Gibson H, Cho RJ. The first report of safety and feasibility of transbronchial cryoprobe lung biopsy in ARDS. Intensive Care Med. 2018;44:971-2.

16. Cooley J, Swank ZG, Aragaki Nakahodo A, Benzaquen S. Safety and utility of transbronchial lung cryobiopsy in mechanically ventilated patients with ARDS. Am J Respir Crit Care Med. 2019;199:A1401.

17. Las Heras MJ, Dianti J, Tisminetzky M, Svetliza G, Giannasi SE, San Roman E. Cryoprobe biopsy for the diagnosis of acute hypoxemic respiratory failure of undetermined origin. J Intensive Care Society. 2019; DOI: 10.1177/1751143719847323

18. Keenan A, Dincer HE, Zamora F, Podgaetz E, Andrade R, Tomic R, et al. The utility and safety of cryo probe lung biopsy in patients with ARDS. Am J Respir Crit Care Med. 2015;191:A1622.

19. Wong AK, Walkey AJ. Open Lung Biopsy Among Critically III, Mechanically Ventilated Patients. A Metaanalysis. Ann Am Thorac Soc. 2015;12:1226-30.

20. Hetzel J, Maldonado F, Ravaglia C, Wells AU, Colby TV, Tomassetti S, et al. Transbronchial Cryobiopsies for the Diagnosis of Diffuse Parenchymal Lung Diseases: Expert Statement from the Cryobiopsy Working Group on Safety and Utility and a Call for Standardization of the Procedure. Respiration. 2018;95:188-200

21. Gnass M, Filarecka A, Pankowski J, Soja J, Bugalho A, Szlubowski A. Transbronchial lung cryobiopsy guided by endobronchial ultrasound radial miniprobe in interstitial lung diseases: preliminary results of a prospective study. Pol Arch Intern Med. 2018;128:259-62.

22. Chang CH, Lee CS, Li SH, Chung FT, Wang CW, Juan YH, et al. Feasibility of Radial Endobronchial Ultrasound-Guided Bronchoscopic Cryobiopsy without Fluoroscopy for Lung Parenchymal Lesions. Can Respir J. 2017;2017:7170687.

\section{Figures}



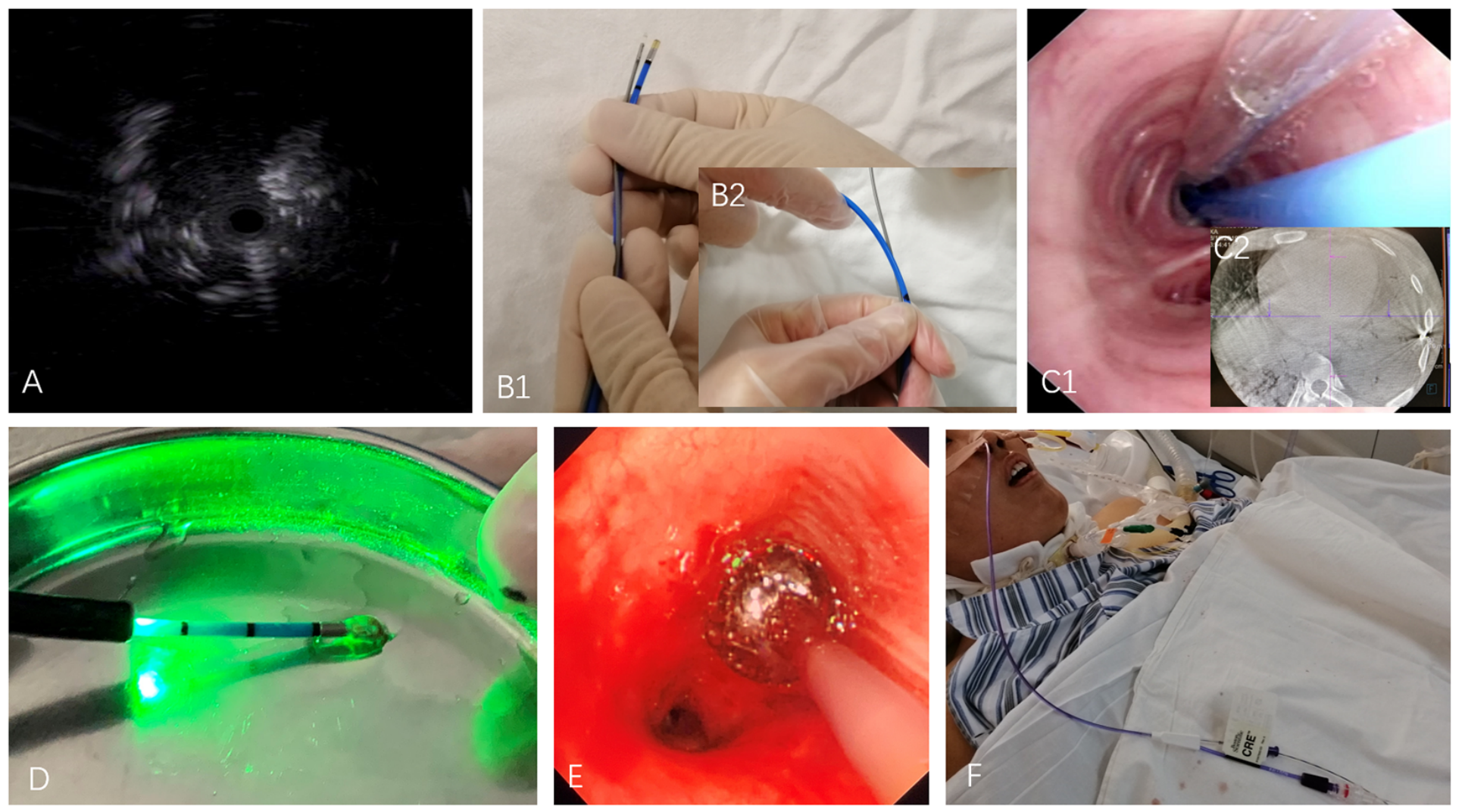

Figure 1

Radial probe endobronchial ultrasound (RP-EBUS) guided transbronchial lung cryobiopsy (TBLC) for acute respiratory distress syndrome (ARDS). (A) RP-EBUS screening the target biopsy position. (B) Marking the biopsy distance on cryoprobe compared to that of RP-EBUS. (C1) Prophylactically placing bronchial blocker and inserting cryoprobe in the target segment. (C2) Combined guidance with cone beam CT after placing cryoprobe in patient 5. (D) Transbronchial lung cryobiopsy was done after freezing $4 \mathrm{~s}$. (E) Bronchial blocker was filled to stop bleeding. (F) Bronchial blocker was continuously placed in target bronchi for the patients with massive bleeding.
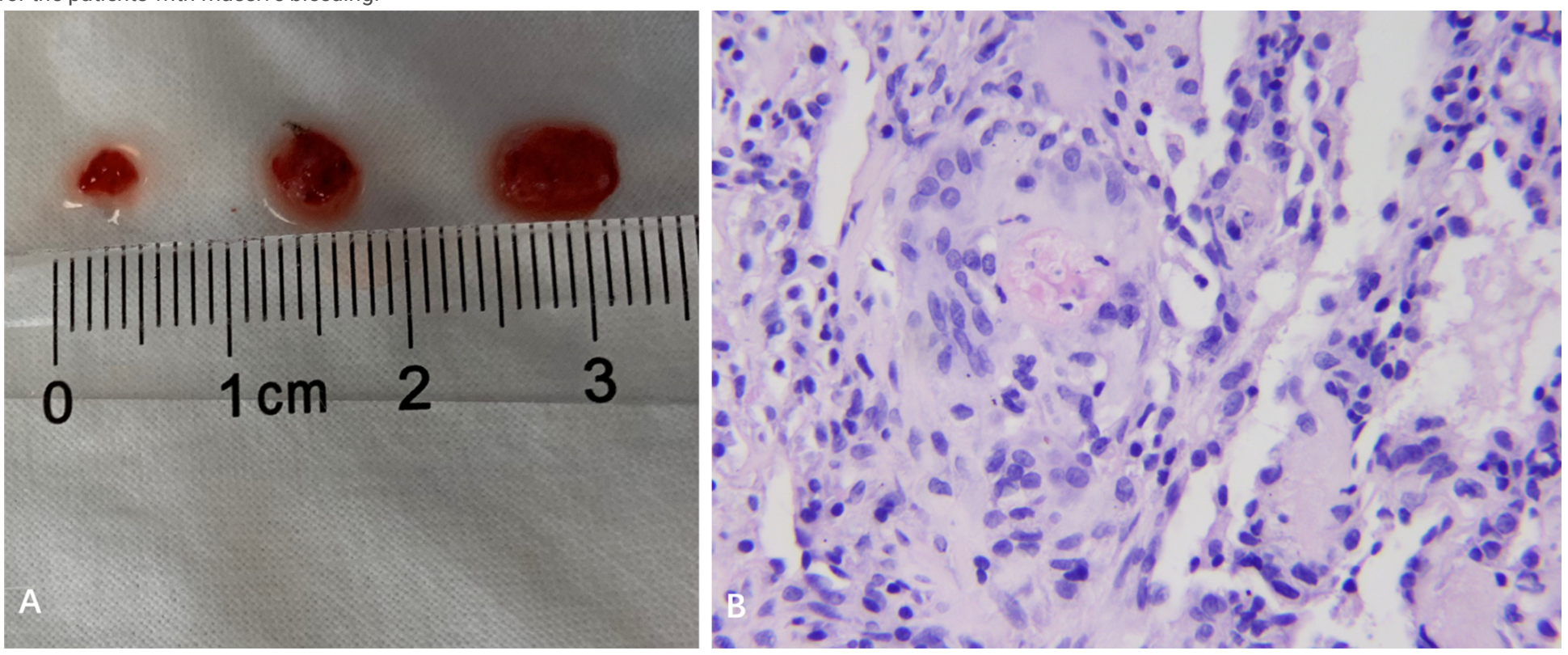

\section{Figure 2}

Specimens and histology obtained by transbronchial lung cryobiopsy for acute respiratory distress syndrome. (A) Gross specimens and their sizes. (B) Histologic diagnosis of foreign body granulomas in patient 3. 


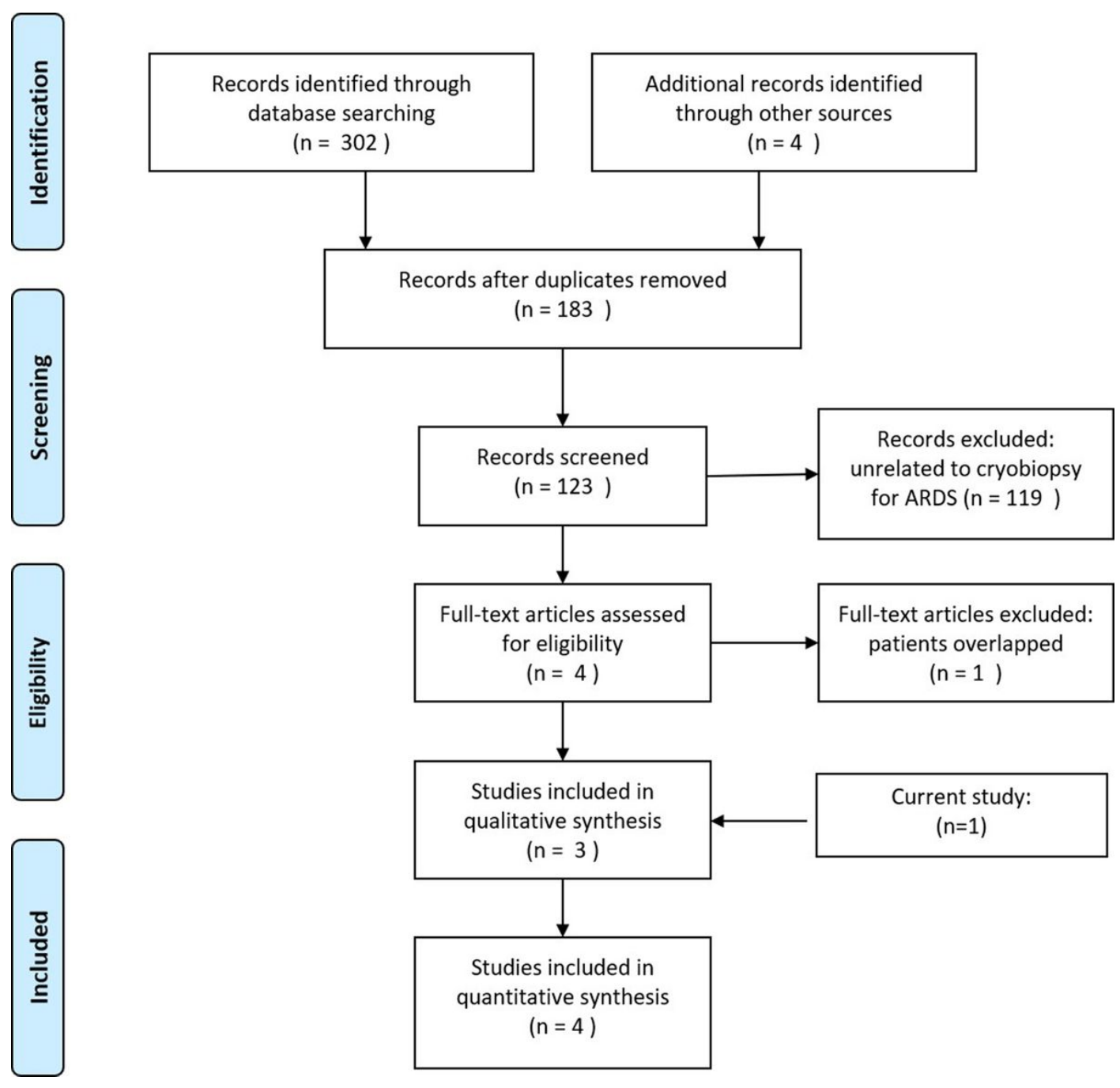

Figure 3

Flow diagram of the literature search and study selection process.

\section{Supplementary Files}

This is a list of supplementary files associated with this preprint. Click to download.

- PRISMA2009checklist.doc 